\title{
Sinonímias e descrições em Adetus LeConte (Coleoptera, Cerambycidae, Lamiinae, Apomecynini)
}

\author{
Ubirajara R. Martins ${ }^{1,3}$ \\ Maria Helena M. Galileo ${ }^{2,3}$
}

\begin{abstract}
Aвstract. Synonymies and descriptions in Adetus LeConte (Coleoptera, Cerambycidae, Lamiinae, Apomecynini). Based on the photographs (color slides) taken from the type specimens of Adetus species, the following synonyms are established: Adetus subcostatus Aurivillius, $1900=$ A. auratoides Breuning, 1943 syn. nov.; A. leucostigma Bates, $1880=$ A. venezuelensis Breuning, 1942 syn. nov.; A. pulchellus (Thomson, 1868) = A. laterialbus Breuning, 1942 syn. nov.; A. irregularis (Breuning,1939) = A. gracilis Breuning, 1940 syn. nov.; A. flavescens Melzer, 1934 = A. strandi Breuning, 1940 syn. nov. = A. mediofasciculatus Breuning, 1943 syn. nov.; A. modestus Melzer, 1934 = Atimuropsis densepunctata Breuning, 1939 syn. nov. New species described: Adetus multifasciatus sp. nov. (Brazil, São Paulo); A. lineatus sp. nov. (Brazil, Distrito Federal); A. linsleyi sp. nov. (Ecuador, Los Ríos); A. pacaruaia sp. nov. (Peru, Huanuco), and A. pinima sp. nov. (Peru, Junin). Adetus marmoratus Breuning, 1942 is redescribed.
\end{abstract}

Keywords. Adetus; Apomecynini; Cerambycidae; Lamiinae; taxonomy.

\section{INTRODUÇÃO}

O gênero Adetus, segundo o catálogo de MonNé (1994), tem 69 espécies que ocorrem nas Américas. Neste trabalho, propomos sete sinonímias e descrevemos cinco espécies. Assim, o gênero fica, no momento, com 67 espécies.

As sinonímias são estabelecidas com base em fotos (diapositivos) dos tipos, tiradas por J. S. Moure. As siglas mencionadas no texto correspondem às seguintes coleções: BMNH, The Natural History Museum, Londres; CASC, California Academy of Sciences, San Francisco; FAUV, Facultad de Agronomia, Universidad Central de Venezuela, Maracay; MNHN, Muséum National d'Histoire Naturelle, Paris; MZSP, Museu de Zoologia, Universidade de São Paulo, São Paulo; NHRS, Naturhistoriska Riksmuseet, Estocolmo; USNM, National Museum of Natural History, Washington.

Adetus LeConte, 1852

Adetus LeConte, 1852: 161; Monné, 1994: 23(cat.).

Espécie-tipo: Polyopsia analis Haldeman, 1847, monotipia.

O gênero Adetus reconhece-se, dentre os gêneros de Apomecynini, pelo seguinte conjunto de caracteres: cabeça retrátil; lobos oculares inferiores do mesmo comprimento ou mais curto do que as genas; antenas sem pêlos no lado inferior ou com franja de pêlos muito esparsa, atingem o meio dos élitros; antenômero III mais longo do que o IV; protórax sem tubérculo lateral; metasterno não-encurtado; cavidades coxais intermediárias abertas no lado.

Adetus subcostatus Aurivillius, 1900

Adetus subcostatus Aurivillius, 1900: 452; Monné, 1994: 31 (cat.). Adetus auratoides Breuning, 1943: 37; Monné, 1994: 25 (cat). Syn. nov.

Aurivillius (1900) descreveu A. subcostatus com base num exemplar da Venezuela sem detalhar a localidade. O holótipo (NHRS) foi examinado por meio de diapositivo.

Adetus auratoides Breuning, 1943 foi descrita com base em síntipos (número não declarado) procedentes de Maracay, Aragua, Venezuela e pertencentes à ex-Coleção Tippmann, hoje no USNM. Um síntipo foi examinado por meio de diapositivo.

Não pudemos encontrar diferenças entre os exemplares dos dois diapositivos nem nas descrições originais e passamos a considerar A. auratoides Breuning, 1943 como sinônimo de $A$. subcostatus Aurivillius, 1900. 
Adetus leucostigma Bates, 1880

Adetus leucostigma Bates, 1880: 108; Monné, 1994: 27 (cat.).

Tautoclines leucostigma; Lameere, 1883: 61 (cat.).

Adetus venezuelensis Breuning, 1942: 139; Monné, 1994: 32 (cat.). Syn. nov.

Adetus leucostigma foi descrita por Bates (1880) com base em diversos síntipos procedentes do México, da Guatemala (Chimantla, 4100 pés; Zapote; San Geronimo) e de Belize (Belize). Em 1885, Bates examinou exemplares do Panamá (Vulcão de Chiriqui) o que indica que a espécie ocupa vasta área. Examinamos o diapositivo de um dos síntipos do BMNH.

Adetus venezuelensis Breuning, 1942 foi descrita com base em um indivíduo de "Venezuela: Sarare". Este topônimo, de acordo com Visintinital et al. (1966), localiza-se no Estado de Portuguesa, contudo MonNÉ (1994) arrolou "Venezuela, Apure: Sarare”. Examinamos o diapositivo do holótipo depositado no MNHN.

Confrontando os diapositivos dos tipos e as descrições originais, concluímos que $A$. venezuelensis Breuning, 1942 é sinônima de A. leucostigma Bates, 1880.

\section{Adetus pulchellus (Thomson, 1868)}

Tautoclines pulchella Thomson, 1868: 156.

Adetus pulchellus; Aurivillius, 1922:289; Monné, 1994: 30 (cat.).

Adetus strigulatus Bates,1880: 107.

Tautoclines strigulata; Lameere, 1883: 57.

Adetus nigricornis Aurivillius, 1900: 412.

Adetus imcomptus Belon, 1902: 469.

Adetus socius Melzer, 1934: 81, est. 1, fig. 5.

Adetus brevicornis Breuning, 1940:151.

Adetus laterialbus Breuning, 1942: 138; Monné, 1994: 27 (cat). Syn. nov.

Adetus pulchellus, espécie de larga distribuição, da Guatemala à Argentina, já foi descrita inúmeras vezes com denominações diversas. O diapositivo do holótipo (MNHN), do Brasil, foi examinado.

Essa espécie foi assinalada por Bates (1880) para a Guatemala (Escuintla: El Zapote) e, em 1885, para o Panamá (Bugaba). Aurivillius (1900) registrou-a para Venezuela (Caracas). Belon (1902) citou-a para a Bolívia (Cochabamba). Melzer (1934) registrou-a para o Brasil (Pernambuco: Gravatá; Minas Gerais: Belo Horizonte) e BRUCH (1939) assinalou-a para a Argentina (Misiones). Bosq (1945) registrou-a para o Paraguai (San Estanislao e Peribebuy) e Franz (1954), para El Salvador. BReuning (1971: 304) acrescentou o Panamá (San Lorenzo), Guiana Francesa, Brasil (Bahia) e Paraguai (Asunción).

Adetus laterialbus descrita por BREUning (1942) com base num exemplar procedente da Argentina (Santiago del Estero, Río Salado, 26 km ao NE de Icaño) é ora sinonimizada com $A$. pulchellus com fundamento no exame do diapositivo do holótipo e na descrição original.

Adetus irregularis (Breuning, 1939)

Atimuropsis irregularis Breuning, 1939: 233.

Adetus irregularis; Breuning, 1960: 180; Monné, 1994: 27 (cat.).
Adetus gracilis Breuning, 1940: 38; Monné, 1994: 27 (cat.). Syn. nov.

Os dois nomes foram aplicados para a mesma espécie, descrita, respectivamente, de Pernambuco, Brasil (A. irregularis, holótipo, BMNH) e do Ceará e de Pernambuco (Serra de Comunati) (A. gracilis, síntipos, MNHN e BMNH). Examinamos os diapositivos do holótipo de A. irregularis e de um síntipo (BMNH) de A. gracilis.

\section{Adetus flavescens Melzer, 1934}

Adetus flavescens Melzer, 1934: 84, est.1. fig. 6; Monné, 1994: 26 (cat.).

Adetus strandi Breuning, 1940: 38; Monné, 1994: 31(cat.). Syn. nov. Adetus mediofasciculatus Breuning, 1943: 37; Monné, 1994: 28 (cat.). Syn. nov.

Melzer (1934) descreveu A. flavescens com base num exemplar do Brasil, São Paulo: Guarujá, que se encontra atualmente no MZSP.

Breuning (1940) descreveu A. strandi do Brasil, Rio de Janeiro: Rio de Janeiro (BMNH), mas assinalou, em 1971, para o Rio de Janeiro (Tijuca) e São Paulo (Rio Pardo) exemplares do MNHN. Pelo diapositivo do holótipo no BMNH, constatamos ser coespecífico com A. flavescens.

Em 1943, Breuning descreveu A. mediofasciculatus, fundamentado num indivíduo do Brasil, Santa Catarina: Blumenau, que foi fotografado no MNHN. BREuning (1971) registrou-a para São Paulo, Paranapiacaba (Alto da Serra).

O exame dos diapositivos dos tipos e do holótipo de $A$. flavescens permitiu propor as sinonímias acima.

Adetus modestus Melzer, 1934

Adetus modestus Melzer, 1934: 83; Monné, 1994: 28 (cat.). Atimuropsis densepunctata Breuning, 1939: 233. Syn. nov.

Adetus densepunctatus; Breuning, 1960: 179 (cat.); Monné, 1994: 26 (cat.).

Melzer (1934) descreveu esta espécie baseado em dois exemplares: Brasil, São Paulo, São Paulo (holótipo, MZSP) e um parátipo de São Paulo, Amparo.

BREUNING (1939) descreveu Atimuropsis densepunctata com base num indivíduo do Brasil, Rio de Janeiro, Rio de Janeiro. O diapositivo do holótipo (BMNH) foi examinado.

Consideramos A. densepunctatus sinônima de A. modestus.

\section{Adetus marmoratus Breuning, 1942}

(Fig. 1)

Adetus marmoratus Breuning, 1942: 138; Monné, 1994: 28 (cat.).

Aproveitamos o ensejo para redescrever e figurar esta espécie.

Tegumento da cabeça castanho-avermelhado recoberto por pubescência esbranquiçada e acastanhada; esta ocupa uma larga área na fronte e no vértice. Lobos oculares inferiores com o dobro do comprimento das genas. Antenas com tegumento avermelhado recoberto por pubescência branco-acinzentada. 
Protórax com tegumento castanho; pubescência predominantemente amarelada com três faixas longitudinais, mais ou menos definidas, da base ao meio: uma no centro e duas laterais. Partes laterais do protórax e prosterno com pubescência predominantemente esbranquiçada.

Élitros com tegumento preto na base e algumas áreas irregulares na metade posterior; pubescência branco-amarelada com manchas de pubescência esbranquiçada ao redor das áreas pretas; pontuação elitral adensada no quarto basal. Ápices elitrais arredondados.

Mesosterno com pubescência alaranjada entremeada por pubescência esbranquiçada. Metasterno e abdômen com pubescência esbranquiçada. Fêmures e tíbias com pubescência amarelada mesclada por pubescência branca e alguns pontos escuros, contrastantes.

Dimensões, em mm, fêmea. Comprimento total 9,4-10,0; comprimento do protórax 2,2-2,2; maior largura do protórax 2,22,4; comprimento do élitro 7,0-7,5; largura umeral 2,8-2,9.

Material examinado. BRASIL. Minas Gerais: Sete Lagoas (Instituto de Pesquisas Agronômicas), fêmea, sem data, V. O. Becker col. São Paulo: Castilho (margem esquerda do Rio Paraná), fêmea, X.1974, Expedição do Departamento de Zoologia col. (MZSP); Itápolis, fêmea, IX.1991, S. Gonçalves col. (MZSP).

\section{Adetus multifasciatus sp. nov.} (Fig. 2)

Cabeça com tegumento preto na fronte e avermelhado no restante; pubescência branco-amarelada, esparsa. Antenas com tegumento avermelhado recoberto por pubescência amarelo-esbranquiçada.

Protórax com tegumento avermelhado e uma larga área no centro do pronoto com tegumento preto; pubescência pronotal branco-amarelada; partes laterais do protórax com pubescência mais alaranjada.

Quarto basal dos élitros com tegumento preto que emite um prolongamento sutural até o terço anterior; uma faixa larga de tegumento preto na metade apical que não alcança a sutura nem os ápices. Pubescência no quarto basal amarelada que, até o meio, é esparsa e está entremeada por muitas faixas estreitas, transversais, irregulares, de pubescência amarelada mais concentrada; metade posterior com duas manchas grandes, laterais, de pubescência esbranquiçada: uma maior depois do meio e uma menor, anteapical. Extremidades elitrais levemente oblíquas.

Face ventral com pubescência esbranquiçada. Fêmures com pubescência amarelada e alguns pontos escuros, contrastantes.

Dimensões, em mm, fêmea. Comprimento total 8,8; comprimento do protórax 1,9; maior largura do protórax 1,8; comprimento do élitro 6,8; largura umeral 2,4.

Material-tipo. Holótipo fêmea, BRASIL. São Paulo: Campos do Jordão (Lagoinha), 13.II.1964, A. A. Rocha col. (MZSP).

Discussão. A. multifasciatus caracteriza-se pela pubescência elitral concentrada em faixas estreitas, transversais, na metade anterior dos élitros.

\section{Adetus lineatus sp. nov.}

(Fig. 3)

Tegumento castanho-avermelhado. Fronte e vértice revestidos por rala pubescência esbranquiçada, com pontos profundos, moderadamente concentrados. Antenas com pubescência esbranquiçada. Pronoto com pubescência esbranquiçada esparsa, mais concentrada em três faixas longitudinais: uma central mais estreita e duas laterais pouco mais largas. Protórax mais longo do que largo. Pontuação pronotal densa e profunda. Partes laterais do protórax com pubescência e pontuação semelhantes às do pronoto. Élitros com pubescência esbranquiçada organizada em faixas longitudinais; os intervalos, entre as faixas de pubescência, densamente pontuados e brilhantes. Largura umeral apenas maior que a largura do protórax. Extremidades elitrais arredondadas. Face ventral com pubescência esbranquiçada e esparsa. Pontuação densa, profunda nos lados do metasterno e dos urosternitos. Pernas avermelhadas com rala pubescência esbranquiçada. Metatíbias engrossadas para o ápice.

Dimensões, em mm, macho. Comprimento total 7,8; comprimento do protórax 2,0; maior largura do protórax, 1,7; comprimento do élitro 5,4; largura umeral 1,8.

Material-tipo. Holótipo macho, BRASIL, Distrito Federal: Taguatinga, 18.VIII.1984, J. Dalmacio col., à luz (MZSP).

Discussão. A. lineatus caracteriza-se pelo padrão de colorido dos élitros representado por faixas longitudinais de pubescência esbranquiçada entremeadas por faixas glabras e pontuadas. Além disso, o protórax é mais longo do que largo e os úmeros não são mais largos que a base do protórax.

\section{Adetus linsleyi sp. nov.}

(Fig. 4)

Etimologia. Epíteto em homenagem póstuma ao Professor E. G. Linsley, grande especialista nos cerambicídeos da América do Norte.

Tegumento avermelhado, mais escuro no pronoto, em pequenas áreas irregulares nos élitros, numa faixa estreita que bordeja anteriormente a larga banda branca apical dos élitros e em duas manchas, suturais, envolvidas pela mesma banda branca.

Fronte e vértice densa e profundamente pontuados. Lobos inferiores dos olhos $(0,3 \mathrm{~mm})$ mais curtos que as genas $(0,6$ $\mathrm{mm}$ ). Antenas avermelhadas com os artículos apicais ligeiramente mais escurecidos. Protórax tão longo quanto largo. Partes laterais do protórax com pilosidade mais densa e pontuação semelhante à do pronoto. Disco pronotal densa e profundamente pontuado. Élitros com um grupo de duas ou três manchas pequenas de pubescência branca, dorsais, ao nível do terço anterior; larga faixa de pubescência branca, curva, que envolve as manchas escuras ante-apicais. Pontuação elitral mais densa na região basal. Face ventral com pontuação nos lados do metasterno e do urosternito I. Mesosterno truncado no lado anterior. Lados dos urosternitos sem manchas circulares 
de tegumento brilhante. Fêmures sem pontos contrastantes. Metatíbias gradualmente engrossadas para o ápice.

Dimensões, em mm, macho. Comprimento total, 7,7-9,1; comprimento do protórax, 2,0-2,3; maior largura do protórax, 2,0-2,3; comprimento do élitro, 5,3-6,5; largura umeral, 2,5-2,9.

Material-tipo. Holótipo macho. EQUADOR, Los Ríos: Pitilingue, 2.II.1955, E. S. Schlinger \& E. S. Ross col., ex-col. E. G. Linsley (CASC). Parátipo macho, da mesma localidade (Quevedo, 100 m), VIII.1974, Bordon col. (MZSP).

Discussão. O parátipo de A. linsleyi sp. nov. está com a pubescência bastante danificada e, segundo Joly (informação pessoal), existem mais quatro exemplares na FAUV.

Adetus linsleyi sp. nov. não pode ser confundida com $A$. analis, pois não apresenta banda branca esbranquiçada nos lados do pronoto; tem pequeno grupo de manchas de pubescência branca no terço anterior; a faixa branca apical dos élitros é larga (Fig. 4); o mesosterno não é fortemente truncado e intumescido e os lados dos urosternitos não apresentam manchas glabras e pretas. Em A. analis, existe a banda de pubescência branca nos lados do pronoto, o pequeno grupo de manchas de pubescência branca situa-se no terço apical dos élitros, a faixa branca que bordeja anteriormente a mancha escura apical dos élitros é estreita, o mesosterno é fortemente saliente e truncado e os lados dos urosternitos têm manchas pretas, glabras.

Adetus lherminieri Fleutiaux \& Sallé, 1889, das Antilhas, examinada por meio do diapositivo de um dos síntipos, apresenta, como A. linsley, uma banda pré-apical, larga, de pubescência branca que atinge a sutura e envolve manchas castanhas. Distingue-se A. linsleyi de A. Iherminieri pelos élitros arredondados no ápice, pelos fêmures lisos, pelo processo mesosternal truncado na frente, pelo pronoto sem banda longitudinal de pubescência amarelada e pela ausência de única mancha circular, pequena, de pubescência branca no meio dos élitros. Segundo Breuning (1971), em A. Iherminieri os ápices dos élitros são subtruncados, os fêmures são densa e finamente pontuados, o processo mesosternal é obliquamente truncado na frente, o pronoto tem uma larga banda longitudinal de pubescência esbranquiçada, esparsa e os élitros têm, ao nível do terço anterior, um grupo de pequenas manchas de pubescência branca.

\section{Adetus pacaruaia sp. nov.}

(Fig. 5)

Etimologia. Tupi, pacaruáia = cauda, alusivo aos ápices elitrais com mancha.

Tegumento preto. Cabeça com duas faixas transversais de pubescência branca: uma, mais larga, na metade inferior da fronte; uma, mais estreita, no dorso da cabeça. A região entre essas faixas com pubescência castanha-avermelhada. Fronte com pontos grandes. Lobos oculares inferiores $(0,3 \mathrm{~mm})$ mais curtos do que as genas $(0,7 \mathrm{~mm})$. Antenas mais avermelhadas para a extremidade. Antenômeros VII-X com anel basal de pubescência branco-acinzentada. Protórax apenas mais largo do que longo. Lados do pronoto com faixas longitudinais de pubescência branca, prolongada até o terço anterior dos élitros; uma outra faixa de pubescência branca, em continuação àquela da fronte, segue pelos lados do protórax, metade inferior dos mesepimeros e mesepisternos e lados do metasterno. Pronoto e partes laterais do protórax densamente pontuados, inclusive no interior da faixa branca pronotal. Élitros revestidos por pubescência castanho-amarelada; ápices elitrais revestidos por pilosidade castanho-escura bordejados anteriormente por faixa larga de pubescência branca que se alarga em direção à margem. Pontuação elitral mais concentrada nos lados da metade anterior. Mesosterno truncado anteriormente. Fêmures com pontos contrastantes. Pontuação esparsa nos lados do metasterno. Manchas glabras nos lados dos urosternitos II a V.

Dimensões, em mm, fêmea. Comprimento total, 11,4; comprimento do protórax, 2,7; maior largura do protórax, 2,8; comprimento do élitro, 8,4; largura umeral, 3,2.

Material-tipo. Holótipo fêmea. PERU, Huanuco: Tingo Maria (2200 m), 19.X.1946, J. C. Pallester col. (AMNH).

Discussão. A. pacaruaia sp.nov. distingue-se de A. analis pela pubescência branca presente na cabeça e em faixa longitudinal nos lados do protórax e do pronoto, nos mesepimeros e mesepisternos, lados do metasterno e no terço látero-basal dos élitros; pela ausência de pequena mancha de pubescência branca no dorso dos élitros; pela faixa branca pré-apical muito mais larga e com pontos contrastantes. Em $A$. analis a cabeça não tem faixas brancas; as faixas pronotais são mescladas por pubescência branca e amarelada e as outras faixas não existem; presença de pequena mancha de pubescência branca no dorso dos élitros; a faixa de pubescência branca anteapical dos élitros é muito estreita e não tem pontos contrastantes.

\section{Adetus pinima sp. nov.}

(Fig. 6)

Etimologia. Tupi, pinima $=$ pintado, em alusão às manchas brancas dos élitros.

Tegumento avermelhado, menos no ápice dos élitros onde é acastanhado. Cabeça revestida por pubescência amarelada. Fronte pontuada. Lobos oculares inferiores $(0,3 \mathrm{~mm})$ mais curtos que as genas $(0,5 \mathrm{~mm})$. Antenas com tegumento avermelhado revestidas por pubescência amarelada. Protórax apenas mais longo do que largo. Pronoto com faixas laterais, longitudinais, de pubescência densa esbranquiçada. Partes laterais do protórax com pubescência amarelo-avermelhada. Élitros recobertos por pubescência branco-amarelada, mais esbranquiçada em faixa longitudinal indistinta que se inicia nos úmeros. Pequenas manchas de pubescência branca dispersas pelos élitros, sendo a dorsal central mais conspícua; faixa estreita, curva, de pubescência branca bordeja as manchas acastanhadas que ocupam os ápices elitrais. Mesosterno arredondado na frente, não-truncado. Mesepimeros e lados do 

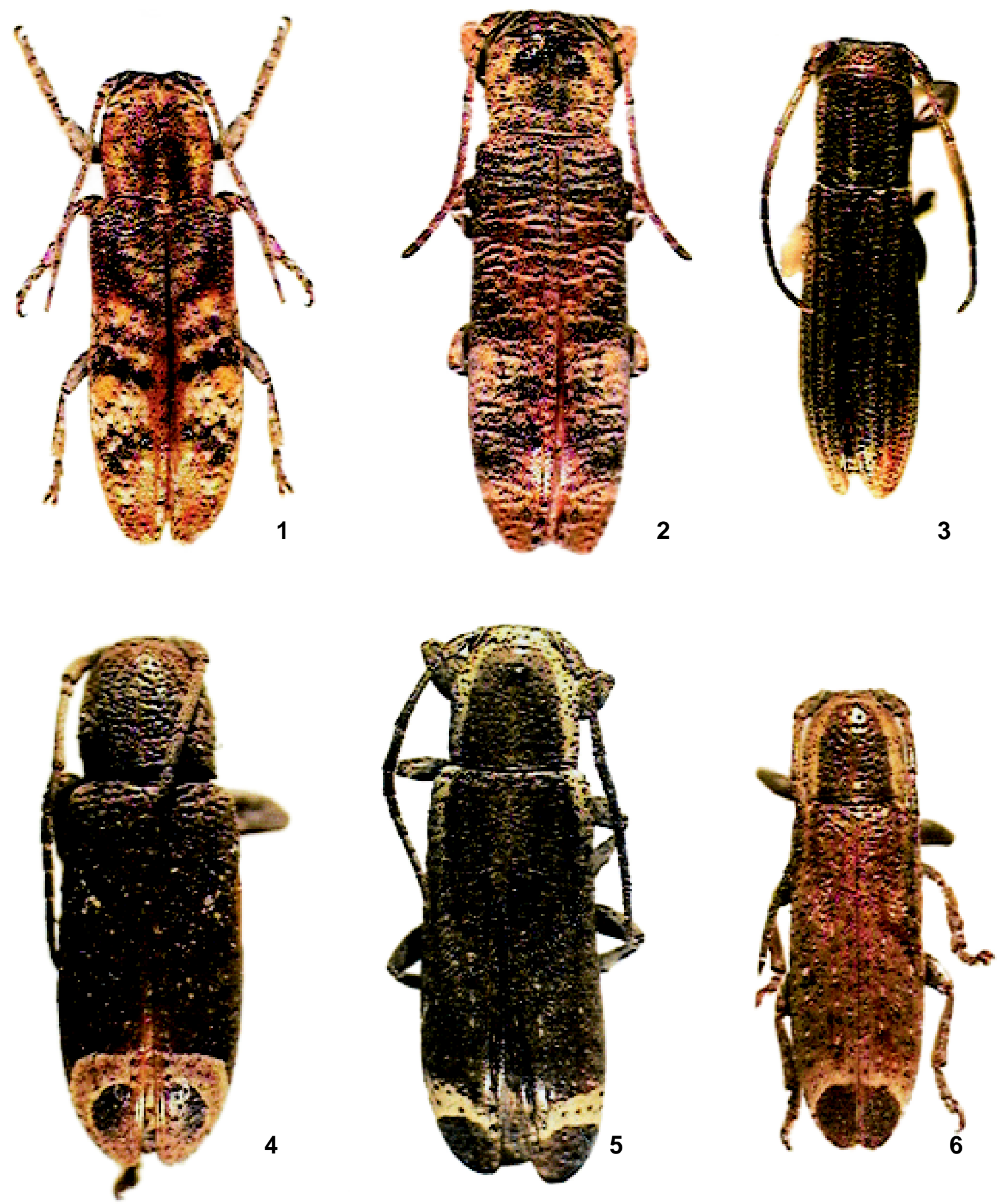

Figs. 1-6. 1, Adetus marmoratus Breuning, 1942, fêmea, comprimento 9,4 mm; 2, Adetus multifasciatus sp. nov., holótipo fêmea, comprimento $8,8 \mathrm{~mm}$; 3, Adetus lineatus sp. nov., holótipo macho, comprimento 7,8 mm; 4, Adetus linsleyi sp. nov., holótipo macho, comprimento 9,1 mm; 5, Adetus pacaruaia sp. nov., holótipo fêmea, comprimento 11,4 mm; 6, Adetus pinima sp. nov., holótipo fêmea, comprimento 8,3 mm. 
metasterno grosseiramente pontuados . Lados dos urosternitos sem manchas glabras.

Dimensões, em mm, fêmea. Comprimento total, 8,3-8,8; comprimento do protórax, 1,9-2,0; maior largura do protórax, 1,8-1,9; comprimento do élitro, 6,1-6,4; largura umeral 1,5-2,2.

Material-tipo. Holótipo fêmea. PERU, Junin: Sani Beni, 10.VI.1937, F. Woytkowiski col., ex-col. E. G. Linsley (CASC). Parátipo fêmea, mesma procedência e coletor do holótipo, ex-col. Van Dyke (MZSP).

Discussão. Distingue-se de A. analis principalmente pelo mesosterno em declive arredondado e sem projeção vertical. Além disso, o aspecto geral é mais esbelto, e não existem as manchas glabras nos urosternitos.

Agradecimento. A Jorge L. Dutra Soledar, bolsista de iniciação científica da Fundação de Amparo à Pesquisa do Rio Grande do Sul junto ao Museu de Ciências Naturais, Porto Alegre, pela execução das fotografias.

\section{REFERÊNCIAS}

AurivilLius, C. 1900. Verzeichniss der von Dr. F. Meinert im Jahre 1891 in Venezuela gesammelten Cerambyciden. Öfversig Svenska Vetens. Akademie Förhandlingar 57: 409-421.

Aurivillius, C. 1922. Coleopterorum Catalogus, pars 73, Cerambycidae: Lamiinae. Berlin, W. Junk, 322 p.

Bates, H. W. 1880. Biologia Centrali-Americana, Insecta, Coleoptera. London, British Museum, 5: 17-152, est. 3-11.

Bates, H. W. 1885. Biologia Centrali-Americana, Insecta, Coleoptera, suppl. to Longicornia. London, British Museum, 5: 249-436, est.1724.

Belon, P. M. 1902. Description de plusieurs longicornes de Bolivie appartenant au genre Adetus LeCo. Annales de la Societé
Entomologique de Belgique 46: 464-472.

BosQ, J. M. 1945. Longicórnios del Paraguay capturados por los padres Bridarolli y Williner S. S. J. J. Revista Argentina de Zoogeografía 5: $46-54$.

Breuning, S. 1939. Novae species Cerambycidarum. VII. Festschricht 60 Geburtast E. Strand 5: 144-290.

Breuning, S. 1940. Novae species Cerambycidarum. VIII. Folia zoologica et hydrobiologica 10: 37-85, 115-214.

BReuning, S. 1942. Novae species Cerambycidarum. XI. Folia zoologica et hydrobiologica 11: 113-175.

Breuning, S. 1943. Novae species Cerambycidarum. XII. Folia zoologica et hydrobiologica 12: 12-66.

Breuning, S. 1960. Catalogue des Lamiaires du Monde (Col., Cerambycidae). 3 Lief. Tutzing bei München, Museum G. Frey, p. 109-182.

Breuning, S. 1971. Révision des espèces américaines de la tribue des Apomecynini Lac. (Coleoptera, Cerambycidae). Entomologische Abhandlungen Museum Tierkunde 37(3): 209-235, 2 figs.

Bruch, C. 1939. Misceláneas entomológicas. II. Notas biológicas sobre dos coleópteros, Adetus similis. Notas del Museo de La Plata 4(Zool. 20): 206-209, 1 pl.

Franz, E. 1954. Cerambycidae (Ins., Col.) aus El Salvador. Senckenbergiana 34(4-6): 213-229, $1 \mathrm{pl}$.

LAmeere, A. A. 1883. Liste des cérambycides, décrits postérieurement au catalogue de Munich. Annales de la Societé Entomologique de Belgique 26: 1-78.

LeConte, J. L. 1852. An attempt to classify the longicorn Coleoptera of the part of America, north of Mexico. Journal of the Academy of Natural Science of Philadelphia (2)2: 139-178.

Melzer, J. 1934. Novos subsidios para o conhecimento dos cerambycideos neotrópicos. Revista de Entomologia 4(1): 70-110.

Monné, M. A. 1994. Catalogue of the Cerambycidae (Coleoptera) of the Western Hemisphere Part XIV. São Paulo, Sociedade Brasileira de Entomologia, 72 p.

Thomson, J. 1868. Matériaux pour servir à une révision des lamites (Cérambycides, Coléoptères). Physis Recueil d'Histoire Naturelle 2(6): 146-200.

Visintin, L.; H. Bayer; W. Goldmann. 1966. Goldmanns grosser weltatlas. München, Deutsche-Gemenschat, vi+332 p. 